\title{
Park proximity, quality and recreational physical activity among mid-older aged adults: moderating effects of individual factors and area of residence
}

Jelle Van Cauwenberg ${ }^{1,2,3^{*}}$, Ester Cerin ${ }^{4}$, Anna Timperio ${ }^{4}$, Jo Salmon ${ }^{4}$, Benedicte Deforche ${ }^{1,2}$ and Jenny Veitch ${ }^{4}$

\begin{abstract}
Background: The transition from active employment to retirement is a potentially critical period for promoting maintenance or development of recreational physical activity in older age. Park proximity and quality might be important correlates of recreational physical activity in this age group. However, research on park-physical activity relationships among mid-older aged adults is limited and inconclusive. Furthermore, while knowledge of individual moderators of park-physical activity relationships is crucial for tailoring interventions, this knowledge is also limited. We investigated relationships between perceived park proximity, park quality and recreational physical activity among mid-older aged adults. Additionally, we examined the potential moderating effects of gender, education level, retirement status, functional limitations and area of residence on these relationships.

Methods: Self-reported data on demographics, functional limitations, park proximity, park quality, recreational walking and other recreational moderate- to vigorous-intensity physical activity (MVPA) were collected among 2700 Australian adults (57-67 years) in 2012. Objective information on area of residence was collected. To examine associations of park-related variables with recreational walking and other recreational MVPA, zero-inflated negative binomial (ZINB) regression models were used.
\end{abstract}

Results: Park proximity significantly interacted with retirement status; non-retired participants who reported living near a park were more likely to participate in recreational walking, whereas no relationship was observed in retired participants. Among those who walked for recreation, higher park quality was related to more weekly minutes of recreational walking. No significant relationships with other recreational MVPA and no moderating effects of gender, education level, functional limitations and area of residence were observed.

Conclusions: Parks may stimulate engagement in recreational walking among non-retirees and more walking among those who already walk. Future research should investigate which environmental factors relate to engagement in recreational walking among retirees and examine whether improvements in park quality actually lead to increases in mid-older aged adults' recreational walking.

Keywords: Retirement, Physical environment, Public open spaces, Leisure

\footnotetext{
* Correspondence: jelle.vancauwenberg@ugent.be

'Department of Public Health, Faculty of Medicine and Health Sciences, Ghent University, De Pintelaan 185, B-9000 Ghent, Belgium

${ }^{2}$ Department of Human Biometry and Biomechanics, Faculty of Physical

Education and Physical Therapy, Vrije Universiteit Brussel, Pleinlaan 2, B-1050

Brussels, Belgium

Full list of author information is available at the end of the article
}

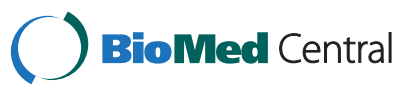

(c) 2015 Van Cauwenberg et al.; licensee BioMed Central. This is an Open Access article distributed under the terms of the Creative Commons Attribution License (http://creativecommons.org/licenses/by/4.0), which permits unrestricted use, distribution, and reproduction in any medium, provided the original work is properly credited. The Creative Commons Public Domain Dedication waiver (http://creativecommons.org/publicdomain/zero/1.0/) applies to the data made available in this article, unless otherwise stated. 


\section{Background}

Worldwide, societies are ageing rapidly and face a burden of age-related diseases with significant economic and social costs [1]. The promotion of physical activity (PA) in the currently insufficiently-active population of mid-older aged adults is an effective strategy to prevent or delay the onset of age-related diseases and facilitate good health and independent living later in life [2,3]. A large proportion of mid-older aged adults in the Westernized world (55-69 years) experience a transitional phase in their lives (e.g., retirement and children leaving home) [4-8]. This transitional phase is a potentially critical period for ensuring maintenance or development of recreational PA, since daily routines and habits may be restructured and more leisure time may become available $[9,10]$.

According to socio-ecological models, engagement in physical activity is determined by the interactions between a person's individual characteristics and the environment in which he or she lives [11-13]. Therefore, the provision of attractive or high quality places for PA can be hypothesized to stimulate participation in recreational PA. Parks are a venue that might particularly stimulate recreational PA. Parks typically provide a green and restorative environment, can be used by whole communities at no/low cost (in comparison to gyms or sports clubs) and may include infrastructure for a variety of recreational physical activities (e.g. walking trails, sports courts) $[14,15]$. Indeed, higher levels of park use have been linked to higher levels of PA $[14,16]$. However, the relationship between park proximity and physical activity remains unclear. Several studies among adults and older adults reported the presence of nearby parks to be positively associated with different measures of physical activity [17-20], whereas other studies found no such relationship [21-24]. Similarly, measures of park quality have been linked to different measures of PA among adults and older adults in some studies [25-28], but not in others [24,29]. To our knowledge, no previous study has examined the relationships of park characteristics with PA specifically among mid-older aged adults.

A possible reason for the observed inconsistencies may be that park proximity and quality are not equally important for all individuals' recreational PA. Relationships of park proximity and quality with recreational PA may be moderated by individual characteristics, such as gender, education level, retirement status, and functional limitations. While such interactions between individuals and their surrounding environments are at the core of socio-ecological models [11-13], this has rarely been studied, particularly among mid-older aged adults $[16,30,31]$. Neighborhood environment-physical activity relationships have been hypothesized to be stronger among older compared to younger adults. Due to retirement, older adults spend more time in their local neighborhood and, therefore, the neighborhood environment may exert a stronger influence on their recreational PA behaviors compared with their employed peers [32,33]. Hence, it could be hypothesized that the relationships of park proximity and quality with recreational PA are stronger among retired than among non-retired mid-older aged adults. Furthermore, press-competence models state that when functional competence decreases, the importance of a supportive neighborhood environment increases because it becomes more difficult to overcome environmental barriers (e.g. large distance to a park) [34]. Therefore, we hypothesized relationships of park proximity and quality with mid-older aged adults' recreational PA to be stronger among those with more compared to less functional limitations. Knowledge of individual moderators is crucial for tailoring interventions to the needs of specific subgroups who are at increased risk of physical inactivity (e.g., women and the functionally limited) [35]. Additionally, the majority of previous research has been conducted in urban areas. Studies in rural areas are scarce [16,36,37], though park visitation and park features have been shown to differ between urban and rural areas [36,38]. Consequently, research is needed to examine whether relationships of park proximity and quality with PA are moderated by area of residence (urban vs. rural).

To summarize, evidence on the relationships between park proximity, quality and recreational PA is inconsistent and not specific to mid-older aged adults. Furthermore, there is a need to study the moderating effects of individual characteristics and area of residence on these relationships. Therefore, the current study aimed to investigate the relationships of perceived park proximity and park quality with recreational walking and 'other' moderate- to vigorous-intensity PA (MVPA) among a sample of Australian mid-older aged adults. Additionally, we examined the potential moderating effects of gender, education level, retirement status, functional limitations and area of residence (urban vs. rural) on these relationships.

\section{Methods}

\section{Procedures and participants}

The current study used data from the Wellbeing, Eating and Exercise for a Long Life (WELL) project, which has been described previously in full detail [39]. Briefly, the WELL study is a cohort study of mid-older adults aged 55-65 years at Time 1 (data collection in 2010) with follow-up at Time 2 (2012). The current study used cross-sectional data collected at Time 2 (measures of park proximity and quality were only introduced at Time 2 ). At Time 1, stratified cluster random sampling was used to recruit 55 to 65 year-olds residing in 84 suburbs that were randomly selected within urban and rural and low, medium, and high socio-economic strata within Victoria, Australia. Within each suburb, 134 participants (50\% women) were randomly selected from the electoral roll 
(registration is compulsory in Australia) and invited to participate through postal mail. One week later, selected participants were sent a self-administered postal questionnaire with a reply-paid envelope. In total, 4,082 completed questionnaires were returned (38\% response rate). Agreement to be re-contacted to participate in a followup questionnaire was obtained from 3368 participants (83\%), of whom 2759 (82\%) returned a questionnaire at Time 2. Participants who reported not being able to perform PA due to health restrictions and those who moved out of the State of Victoria between Time 1 and Time 2 were excluded, resulting in a final sample of 2700 participants. The Deakin University Human Research Ethics Committee approved the study protocol.

\section{Measures}

\section{Recreational walking and other recreational MVPA}

Recreational walking and other recreational MVPA was assessed using the self-administered long version of the International Physical Activity Questionnaire (IPAQ-L), which has excellent test-retest reliability and acceptable validity in adults aged 15-69 years [40]. The IPAQ-L assessed the number of days in the last seven days during which participants walked for at least 10 minutes at a time for recreation. Consecutively, it assessed the average duration of walking on these days (hours and minutes/day). Frequency and duration were multiplied to obtain the variable 'recreational walking'; expressed in minutes per week. Engagement in other recreational MVPA was assessed and calculated similarly. Participants were asked to indicate on how many days and for how long they were physically active at moderate (e.g. bicycling at a regular pace, swimming at a regular pace, and playing doubles tennis) and at vigorous intensity levels (e.g. aerobics, running, fast bicycling, or fast swimming) [40]. It is possible to undertake some of these other MVPA, such as running, cycling and some sports, in parks.

\section{Perceived park proximity and park quality}

Perceived park proximity was assessed by asking the participants how long it would take them to walk from their home to the nearest park. This item was taken from the Neighborhood Environment Walkability Scale (NEWS) and standard scoring protocols were applied $[41,42]$. To assess satisfaction with park quality, participants indicated how much they agreed or disagreed with the statement 'I am satisfied with the quality of parks in my neighbourhood'. Response options were a five-point Likert scale ranging from strongly disagree (1) to strongly agree (5). This variable was used as a proxy for perceived park quality.

\section{Individual factors}

The following individual factors were assessed: date of birth, gender, education level, marital status, retirement status, years living at current address, and functional limitations. The physical functioning scale within the validated Short-Form 36-item Health Survey assessed functional limitations $[43,44]$. Participants indicated their level of limitation in performing ten activities of daily living (e.g., climbing several flights of stairs, vigorous activities such as running lifting heavy objects and participating in strenuous sports, lifting or carrying groceries, bending, kneeling or stooping, etc.) as: limited a lot (1), limited a little (1), or not limited (0).Activities in which participants reported to be limited a lot or a little were summed to create the variable 'number of functional limitations'.

\section{Area-level variables}

Suburbs were initially classified as urban or rural as reported by Cleland et al. [45]. Urban areas of Victoria included: (1) metropolitan Melbourne and (2) postcodes included within a $10 \mathrm{~km}$ radius of the centroid of regional cities (population $>20,000$ ). Areas outside metropolitan Melbourne and more than $25 \mathrm{~km}$ from the center of regional cities were classified as rural. Participants residing in a suburb in a 'fringe' local government area of Metropolitan Melbourne were excluded from the study at Time 1. Forty-five participants who moved to a fringe area between Times 1 and 2 were excluded from the moderation analysis of area of residence due to the small subsample size, but they were included in all remaining main effect and moderation analyses of this study.

The Socio-Economic Index For Areas (SEIFA), consisting of four measures of relative socio-economic (dis)advantage, economic resources, education and occupation, assigned by the Australian Bureau of Statistics [4] was used as an indicator for area-level socio-economic status (SES). Area-level SES was used as a covariate in all analyses.

\section{Statistical analyses}

All analyses were conducted using Stata 10.1. To examine associations of park-related variables with the PA outcomes, zero-inflated negative binomial (ZINB) regression models with robust standard errors accounting for the hierarchical data structure (participants clustered within suburbs) were used. These models were used as the dependent variables were positively skewed and contained a large number of zero values. Vuong tests supported the need to use zero-inflated regression models [46]. ZINB models evaluate the relationships between the independent variables and the odds of nonparticipation in recreational walking/other recreational MVPA. Simultaneously, ZINB models estimate the relationships with weekly minutes of recreational walking/ other recreational PA for participants who did engage in some recreational walking/other recreational PA. Hence, one ZINB model yields two regression coefficients for each independent variable: an odds ratio (OR) (for the 
relationship between the independent variable and the odds of not engaging in recreational walking/other recreational PA) and a negative-binomial model regression coefficient (representing the proportional change in minutes/week recreational walking or other recreational MVPA with a one-unit increase in the independent variable for participants engaging in recreational walking/ other recreational PA).

First, a model that included the main effects of perceived park proximity, quality and all potential moderators was estimated. Second, five models were estimated which included the main effects and the interaction effect between the independent variables (perceived proximity and quality) and one of the five potential moderators. Third, a final model was built that combined the main effects with all significant moderators observed in the previous step. To keep the table simple and readable, we presented the results obtained in the first model in table and significant interaction effects observed in the final model were described in text. Significant interaction terms were probed according to established procedures [47]. Age and suburblevel socio-economic status were included as covariates in all analyses. All analyses with recreational walking as the dependent variable included other recreational MVPA as a covariate (and vice versa). Level of significance was determined at $\alpha=0.05$.

\section{Results}

\section{Sample characteristics}

Participants had a mean age of $62.3( \pm 3.1)$ years, $52.9 \%$ of the sample were women, $29.9 \%$ had obtained a university degree, $78.1 \%$ lived with a partner, $44.3 \%$ were retired, and $52.2 \%$ resided in a rural area (see Table 1 ). Participants reported a median of 15.0 years living at the current address and a mean of $2.7( \pm 2.6)$ functional limitations. The median value of walking for recreation was 70.0 minutes/week (mean \pm standard deviation $=152.4 \pm$ 212.3) and that of non-walking recreational MVPA was zero minutes/week (mean \pm standard deviation $=97.1 \pm$ 201.7).

\section{Relationships with recreational walking}

The logit model shows that perceived park proximity was significantly negatively related to the odds of nonparticipation in recreational walking (see Table 2). However, this relationship appeared to be significantly moderated by retirement status (OR interaction effect $=1.22$; $95 \% \mathrm{CI}=1.05,1.43$; not shown in Table 2). In nonretired participants, a one-unit increase in park proximity was related to $14 \%$ lower odds of non-participation in recreational walking $(\mathrm{OR}=0.86 ; 95 \% \mathrm{CI}=0.79,0.94)$. In other words, non-retired participants who perceived that they lived near a park were more likely to participate in recreational walking. In contrast, park proximity was not
Table 1 Sample characteristics, perceived park proximity and quality and physical activity

\begin{tabular}{|c|c|}
\hline \multicolumn{2}{|l|}{ Individual factors } \\
\hline Age $(M \pm S D \text {, years })^{a}$ & $62.3 \pm 3.1$ \\
\hline Gender (\% women) & 52.9 \\
\hline \multicolumn{2}{|l|}{ Education level (\%) } \\
\hline$<12$ years of education & 33.9 \\
\hline Year 12/trade/apprenticeship/certificate/diploma ${ }^{a}$ & 36.2 \\
\hline University degree & 29.9 \\
\hline \multicolumn{2}{|l|}{ Marital status (\%) } \\
\hline Living with a partner & 78.1 \\
\hline Separated/divorced/never married & 16.9 \\
\hline Widowed & 5.0 \\
\hline Retirement status (\% retired) & 44.3 \\
\hline Years living at current address (Mdn; Q1-Q3) & $15.0 ; 7.0-28.1$ \\
\hline Functional limitations ( $\mathrm{M} \pm \mathrm{SD}$, number) & $2.7 \pm 2.6$ \\
\hline \multicolumn{2}{|l|}{ Area of residence (\%) } \\
\hline Rural & 52.2 \\
\hline Fringe & 1.7 \\
\hline Urban & 46.1 \\
\hline
\end{tabular}

\section{Park characteristics}

Perceived park proximity $(\mathrm{M} \pm \mathrm{SD}, / 5)^{\mathrm{C}} \quad 3.9 \pm 1.3$

Perceived park quality $(\mathrm{M} \pm \mathrm{SD}, / 5)^{\mathrm{d}} \quad 3.8 \pm 0.9$

Dependent variables

Walking for recreation, mins/week (Mdn; Q1-Q3) 70.0; $0.0-210.0^{e}$

Other recreational PA, mins/week (Mdn; Q1-Q3) $\quad 0.0 ; 0.0-120.0^{\mathrm{e}}$

$\mathrm{M}=$ Mean; $\mathrm{SD}=$ Standard Deviation; $\mathrm{Mdn}=$ Median; $\mathrm{Q} 1$ = quartile 1;

Q3 = quartile 3.

an Australia this refers to non-university tertiary education.

${ }^{\mathrm{b}}$ For normally distributed continuous variables, means and standard deviations were presented. For non-normally distributed continuous variables, medians and interquartile ranges were presented.

'Perceived park proximity was assessed by asking the participants how long it would take them to walk from their home to the nearest park: $1-5$ mins (5), 6-10 mins (4), 11-20 mins (3), 21-30 mins (2), 31+ mins (1), or don't know (1). The option 'don't know' was selected by $2.8 \%$ of the participants.

${ }^{\mathrm{d}}$ Perceived park quality was measured on a five-point scale ranging from strongly disagree (1) to strongly agree (5) with the statement 'I am satisfied with the quality of parks in my neighbourhood'.

eWalking for recreation, mins/week $(M \pm S D)=152.4 \pm 212.3$.

Other recreational MVPA, mins/week $(M \pm S D)=97.1 \pm 201.7$.

significantly related to the odds of non-participation in recreational walking among retired participants $(\mathrm{OR}=1.06$; $95 \% \mathrm{CI}=0.95,1.19)$. Park quality was not significantly related to the odds of non-participation in recreational walking.

Regression coefficients in the negative binomial model showed that park proximity was not significantly related to weekly minutes of recreational walking. However, park quality was significantly positively related to weekly minutes of recreational walking with a one-unit increase in park quality related to $2 \%$ more weekly minutes of 
Table 2 Main effects of the potential moderators, perceived park proximity, and quality

\begin{tabular}{|c|c|c|c|c|}
\hline & Recreational walking & Other recreational MVPA & & \\
\hline & $\begin{array}{l}\text { Logit model: OR of being } \\
\text { non-participant }{ }^{\mathrm{a}}(95 \% \mathrm{Cl})\end{array}$ & $\begin{array}{l}\text { Negative binomial } \\
\text { model: } \min / \text { week } \\
(95 \% \mathrm{Cl})\end{array}$ & $\begin{array}{l}\text { Logit model: OR of } \\
\text { being non-participant } \\
(95 \% \mathrm{Cl})\end{array}$ & $\begin{array}{l}\text { Negative binomial } \\
\text { model: } \mathrm{min} / \text { week } \\
(95 \% \mathrm{Cl})\end{array}$ \\
\hline \multicolumn{5}{|l|}{ Potential moderators } \\
\hline Gender (ref. = male) & $0.72(0.59,0.88)^{* *}$ & $0.99(0.90,1.90)$ & $0.85(0.70,1.04)$ & $0.85(0.74,0.99)^{*}$ \\
\hline \multicolumn{5}{|l|}{$\begin{array}{l}\text { Education level (ref. }=\leq 10 \text { years } \\
\text { of education) }\end{array}$} \\
\hline $\begin{array}{l}\leq 12 \text { years of education/trade/ } \\
\text { certificate }\end{array}$ & $0.86(0.68,1.99)$ & $1.04(0.93,1.17)$ & $0.80(0.64,0.99)^{*}$ & $1.00(0.86,1.17)$ \\
\hline University degree & $0.77(0.61,0.96)^{*}$ & $0.97(0.97,1.08)$ & $0.47(0.38,0.61)^{* * *}$ & $0.88(0.75,1.04)$ \\
\hline Retirement status (ref. = non-retired) & $0.79(0.63,0.97)^{*}$ & $1.31(1.19,1.45)^{* * *}$ & $0.87(0.69,1.08)$ & $1.18(1.06,1.32)^{* *}$ \\
\hline Functional limitations & $1.14(1.09,1.17)^{* * *}$ & $0.95(0.93,0.97)^{* * *}$ & $1.16(1.12,1.22)^{* * *}$ & $0.95(0.92,0.98)^{* *}$ \\
\hline \multicolumn{5}{|l|}{ Area of residence (ref. = urban) } \\
\hline Rural & $0.82(0.64,1.05)$ & $1.04(0.95,1.15)$ & $1.09(0.87,1.38)$ & $0.90(0.77,1.06)$ \\
\hline Fringe & $0.90(0.43,1.92)$ & $0.84(0.63,1.11)$ & $1.34(0.70,2.56)$ & $0.77(0.49,1.20)$ \\
\hline \multicolumn{5}{|l|}{ Park characteristics } \\
\hline Park proximity & $0.91(0.85,0.98)^{* *}$ & $1.03(0.99,1.07)$ & $0.98(0.91,1.05)$ & $0.98(0.93,1.04)$ \\
\hline Park quality & $1.00(0.98,1.02)$ & $1.02(1.01,1.02)^{* * *}$ & $0.94(0.85,1.03)$ & $1.01(0.94,1.10)$ \\
\hline
\end{tabular}

$\mathrm{OR}=$ odds ratio; $\mathrm{Cl}=$ confidence interval; ${ }^{*} \mathrm{p}<0.05 ;{ }^{* *} \mathrm{p}<0.01 ; * * \mathrm{p}<0.001$.

${ }^{\mathrm{a}} \mathrm{OR}$ of being non-participant in recreational walking; ${ }^{\mathrm{b}} \mathrm{OR}$ of being non-participant in other recreational MVPA.

ZINB models evaluate two processes simultaneously. In the logit model, they analyze the relationships between the independent variables and the odds of non-participation in recreational walking or other recreational MVPA. In the negative binomial model, they analyze the relationships with weekly minutes of recreational walking or other recreational MVPA for participants who did engage in some recreational walking or other recreational MVPA. Negative binomial model parameters represent the proportional increase in minutes/week recreational walking or other recreational MVPA with a one-unit increase in the predictor. The model for recreational walking included 2303 observations, of which 757 were zero observations, and was adjusted for age, suburb SES, and other recreational MVPA.

The model for other recreational MVPA included 2298 observations, of which 1406 were zero observations, and was adjusted for age, suburb SES, and recreational walking.

recreational walking. No significant moderating effects were observed in the negative binomial model.

\section{Relationships with other recreational MVPA}

No significant relationships or moderating effects were found for park proximity and quality with other recreational MVPA in the logit or negative binomial part of the model (see Table 2).

\section{Discussion}

The current study showed that self-reported perceptions of park proximity and quality were related to recreational walking but not to other recreational MVPA. Although other studies have shown park users to engage in moderate- and vigorous-intensity park-based activity $[48,49]$, the current study showed that park proximity and quality might be important for stimulating recreational walking more than other forms of recreational PA among mid-older aged adults. This seems to suggest that other park-related variables not included in this study, such as the presence of specific features within parks (e.g., a sports facility), may be more important for higher intensity PA [17]. However, Schipperijn et al. [50] found that park features specifically aimed at PA did not relate to the use of a park for PA among 18- to 80-yearold Danish adults.

We found perceived park proximity and quality to be related to different levels of engagement in recreational walking. Proximity was related to engaging in any recreational walking, while park quality was related to the volume of recreational walking among those who walked for recreation. This supports findings in Australian (mean age 41 yrs.) [51] and Canadian (mean age 46 yrs.) adults [52], in which proximity-measures were related to engaging in any recreational walking or MVPA, whereas quality-measures (attractiveness and size) were related to achieving sufficient amounts of PA to obtain health benefits. Hence, having a nearby park might stimulate adults to walk to and in this park, but a high park quality might be necessary to encourage adults to spend time walking in the park and accumulate more minutes of walking. These findings are consistent with the the Transtheoretical Model, which hypothesizes that different determinants influence people's health behaviours at different stages of change (e.g. contemplating about engaging in any recreational walking vs. already walking 
and maintaining this current level of recreational walking) [53]. Our findings indicate that the provision of a nearby park may stimulate older adults to start walking for recreation. On the other hand, increasing park quality may promote increased recreational walking in those who already walk for recreation. Not taking into account that environmental factors might relate differently to different "stages" of recreational walking might partially explain the inconsistent findings in previous studies [54]. More research is needed to disentangle how different characteristics of parks relate to different levels of engagement in recreational physical activity.

We observed an interaction effect between perceived park proximity and retirement status with higher park proximity related to an increased likelihood of engaging in any recreational walking, but only in those who were not retired. This contradicts our hypothesis that relationships would be stronger among retired older adults since they spend more time in their local neighborhood $[32,33]$. This unexpected finding may be explained by retirees having sufficient time available to travel to a park located further away, making park proximity less important. In contrast, due to time constraints non-retired adults might only engage in recreational walking if a park is located nearby their home. The concept of time budget is frequently used in transportation research, but to our knowledge has not been studied in the field of environment-PA relationships $[55,56]$. Alternatively, it might be that retirees have different activity patterns compared with non-retirees and, therefore, environmental characteristics other than park proximity (such as street design and traffic safety) may be more important to stimulate recreational walking among retirees. More research is needed to examine the influence of retirement on physical activity patterns and its moderating effect on environment-PA relationships.

A strength of the present study is its focus on midolder aged adults, a relevant but understudied population who were living in urban and rural areas across suburbs with varying SES. Additionally, we examined possible moderating effects of several individual factors and area of residence. Knowledge of such moderating effects is limited despite their importance for effective intervention development [31]. The present study is limited by its exclusive reliance upon subjective rather than objective measures of park proximity and quality. Although, agreement between subjective and objective measures of park characteristics has been found to be low $[57,58]$ both are hypothesized to have distinct influences on physical activity behaviors [59,60]. Schipperijn et al. [61] found subjective distance to the nearest park to be a better predictor of frequency of park use than objective distance. Future studies should include both subjective and objective measures of park characteristics to examine how they relate to recreational PA. Further, we assessed proximity and quality of the nearest park and it has been shown that the nearest park is not always the most frequently visited park [61]. Including measures of both the nearest and the most frequently visited park, would enable examination of which park characteristics are related to park visitation. In addition, perceived park quality was not assessed directly, but through a single-item question assessing satisfaction with park quality. Future studies may also benefit from the inclusion of a multi-item measure that includes different aspects of park quality (e.g. nuisance, presence of specific facilities etc.) to better understand which specific park characteristics are related to mid-older aged adults recreational PA. Furthermore, we assessed overall selfreported recreational walking and MVPA rather than park-based walking or MVPA which might have obscured the relationships with park proximity and quality. Combining Global Positioning System devices with accelerometry would yield objective and context-specific PA measures. While neighbourhood walkability (a composite index including residential density, street connectivity and land use mix diversity) has been linked previously to recreational walking among Belgian and US adults [62,63], it was not included in the WELL study. However, all current analyses were adjusted for 'area of residence', which might act as a proxy for neighborhood walkability since urban areas are typically denser and have a higher land use mix diversity than rural areas. Finally, the cross-sectional analyses do not allow us to infer causality; however, Kaczynski and Mowen [64] reported relationships between park availability and park-based PA to be preserved after accounting for residential self-selection. On the other hand, persons who are physically active may visit parks more often and, therefore, be more aware of park quality (i.e. poor park quality) than inactive persons who may visit parks less often. Longitudinal and experimental research is needed to establish causal relationships.

To conclude, non-retired mid-older aged adults who reported living near a park were more likely to engage in recreational walking compared to those living further away. No such relationship was observed among retirees. This seems to suggest that other environmental factors (e.g. street design and traffic safety) may be more important than park proximity in order to increase PA levels among retired persons. Better perceived park quality was related to the accumulation of more minutes of recreational walking among those who walked for recreation independently of retirement status, gender, education and functional level, and area of residence. The current findings imply that parks may stimulate engagement in recreational walking among non-retirees and more walking among those who already walk. Future 
research should investigate which environmental factors relate to engagement in recreational walking among retirees. Natural experiments are needed to examine whether improvements in park quality actually lead to increases in mid-older aged adults' recreational walking.

\section{Competing interests}

The authors declare that they have no competing interests.

\section{Authors' contributions}

JVC, EC, AT, JS, BD and JV contributed to the development of the current study and research questions. EC and JVC performed the data analysis. JVC drafted the manuscript and all other authors critically reviewed and revised versions of the manuscript. All authors read and approved the final manuscript.

\section{Acknowledgements}

This project was supported by the Australian Research Council (DP1095595, FT100100581) and a Diabetes Australia Research Trust Project Grant. JVC was supported by a Ph.D. Fellowship - Research Foundation Flanders (FWO). EC is supported by an Australian Research Council Future Fellowship (FT140100085). JV is supported by a National Health and Medical Research Council Early Career Fellowship (ID 1053426). AT is supported by a Fellowship (Award ID 100046) from the National Heart Foundation of Australia. JS is supported by a National Health and Medical Research Council Principal Research Fellowship (APP1026216).

\section{Author details}

${ }^{1}$ Department of Public Health, Faculty of Medicine and Health Sciences, Ghent University, De Pintelaan 185, B-9000 Ghent, Belgium. ${ }^{2}$ Department of Human Biometry and Biomechanics, Faculty of Physical Education and Physical Therapy, Vrije Universiteit Brussel, Pleinlaan 2, B-1050 Brussels, Belgium. ${ }^{3}$ Fund for Scientific Research Flanders (FWO), Egmontstraat 5, B-1000 Brussels, Belgium. ${ }^{4}$ School of Exercise \& Nutrition Sciences, Deakin University, Burwood Highway 221, Burwood, VIC 3125, Australia.

Received: 27 October 2014 Accepted: 23 March 2015

Published online: 02 April 2015

\section{References}

1. U.S. Census Bureau. International Data Base. 2013. http://www.census.gov/ population/international/data/idb/informationGateway.php.

2. Chodzko-Zajko WJ, Proctor DN, Singh MAF, Minson CT, Nigg CR, Salem GJ, et al. Exercise and physical activity for older adults. Med Sci Sports Exerc. 2009:41:1510-30.

3. Armstrong T, Bauman A, Davies J. Physical activity patterns of Australian adults. In: Physical activity patterns of Australian adults. Australia: Australian Institute of Health and Welfare; 2000.

4. ABS. 2009-10 Household Expenditure Survey (HES). Canberra, Australia: Australian Bureau of Statistics; 2011.

5. Jones J, Saad L. Gallup poll social series: economy and personal finance. USA: Gallup; 2014.

6. United States Census Bureau. America's Families and Living Arrangements: 2013: Households (H table series). USA: United States Census Bureau; 2013.

7. Office for National Statistics. Pension Trends - Chapter 4: The Labour Market and Retirement. 2013th ed. UK: Office for National Statistics; 2013.

8. ABS. Retirement and retirement intentions Australia. Canberr, Australia: Australian Bureau of Statistics; 2013.

9. Beck F, Gillison F, Standage M. A theoretical investigation of the development of physical activity habits in retirement. Br J Health Psychol. 2010;15:663-79.

10. Evenson KR, Rosamond WD, Cai JW, Diez-Roux AV, Brancati FL, Atherosclerosis Risk Comm Study I. Influence of retirement on leisure-time physical activity - The atherosclerosis risk in communities study. Am J Epidemiol. 2002;155:692-9.

11. Stokols D. Translating social ecological theory into guidelines for community health promotion. Am J Health Promot. 1996;10:282-98.

12. Sallis JE, Cervero RB, Ascher W, Henderson KA, Kraft MK, Kerr J. An ecological approach to creating active living communities. Annu Rev Public Health. 2006;27:297-322
13. Alfonzo MA. To walk or not to walk? the hierarchy of walking needs. Environ Behav. 2005;37:808-36.

14. Bedimo-Rung AL, Mowen AJ, Cohen DA. The significance of parks to physical activity and public health - A conceptual model. Am J Prev Med. 2005;28:159-68.

15. De Vries S. Nearby nature and human health: looking at mechanisms and their implications. In: Ward Thompson C, Aspinall P, Bell S, editors. Innovative approaches to researching landscape and health Open space: people space 2. New York: Routledge; 2010.

16. Kaczynski AT, Henderson KA. Parks and recreation settings and active living: a review of associations with physical activity function and intensity. J Phys Act Health. 2008;5:619-32.

17. Cohen DA, McKenzie TL, Sehgal A, Williamson S, Golinelli D, Lurie N. Contribution of public parks to physical activity. Am J Public Health 2007:97:509-14.

18. Roux AVD, Evenson KR, McGinn AP, Brown DG, Moore L, Brines S, et al. Availability of recreational resources and physical activity in adults. Am J Public Health. 2007;97:493-9.

19. Mowen A, Orsega-Smith E, Payne L, Ainsworth B, Godbey G. The role of park proximity and social support in shaping park visitation, physical activity, and perceived health among older adults. J Phys Act Health. 2007:4:167-79

20. Li FZ, Fisher KJ, Brownson RC, Bosworth M. Multilevel modelling of built environment characteristics related to neighbourhood walking activity in older adults. J Epidemiol Community Health. 2005;59:558-64.

21. Jilcott SB, Evenson KR, Laraia BA, Ammerman AS. Association between physical activity and proximity to physical activity resources among low-income, midlife women. Prev Chron Dis. 2007:4:1-16.

22. Nagel $\mathrm{CL}$, Carlson NE, Bosworth M, Michael YL. The relation between neighborhood built environment and walking activity among older adults. Am J Epidemiol. 2008;168:461-8.

23. Witten $\mathrm{K}$, Hiscock R, Pearce J, Blakely T. Neighbourhood access to open spaces and the physical activity of residents: a national study. Prev Med. 2008;47:299-303.

24. Koohsari MJ, Karakiewicz JA, Kaczynski AT. Public open space and walking: the role of proximity, perceptual qualities of the surrounding built environment, and street configuration. Environ Behav. 2013;45:706-36.

25. Bai H, Stanis SAW, Kaczynski AT, Besenyi GM. Perceptions of neighborhood park quality: associations with physical activity and body mass index. Ann Behav Med. 2013;45:S39-48.

26. Giles-Corti B, Broomhall MH, Knuiman M, Collins C, Douglas K, Ng K, et al. Increasing walking - How important is distance to, attractiveness, and size of public open space? Am J Prev Med. 2005;28:169-76.

27. Kaczynski AT, Potwarka LR, Saelens BE. Association of park size, distance, and features with physical activity in neighborhood parks. Am J Public Health. 2008;98:1451-6.

28. Sugiyama T, Thompson CW. Associations between characteristics of neighbourhood open space and older people's walking. Urban For Urban Gree. 2008;7:41-51.

29. Sugiyama T, Thompson CW, Alves S. Associations between neighborhood open space attributes and quality of life for older people in Britain. Environ Behav. 2009;41:3-21.

30. Van Cauwenberg J, De Bourdeaudhuij I, De Meester F, Van Dyck D, Salmon J, Clarys P, et al. Relationship between the physical environment and physical activity in older adults: a systematic review. Health Place. 2011;17:458-69.

31. Ding D, Gebel K. Built environment, physical activity, and obesity: what have we learned from reviewing the literature? Health Place. 2012;18:100-5.

32. Buffel T, Verté D, De Donder L, De Witte N, Dury S, Vanwing T, et al. Theorising the relationship between older people and their immediate social living environment. Int J Lifelong Educ. 2012;31:13-32.

33. Peace $\mathrm{S}$, Wahl HW, Mollenkopf H, Oswald F. Environment and ageing. London: Sage; 2007.

34. Wahl H-W, Lang FR. Aging in context across the adult life course: integrating physical and social environmental research perspectives. In: Werner SK, editor Annual review of gerontology and geriatrics: focus on aging in context: socio-physical environments. Volume 23. New York: Springer Publishing Company; 2003. p. 1-33.

35. Kremers S, de Bruijn G-J, Visscher T, van Mechelen W, de Vries N, Brug J. Environmental influences on energy balance-related behaviors: A dual-process view. Int J Behav Nutr Phys Act. 2006, 3. 
36. Veitch J, Salmon J, Ball K, Crawford D, Timperio A. Do features of public open Spaces vary between urban and rural areas? Prev Med. 2013;56:107-11.

37. Cerin E, Lee KY, Barnett A, Sit CHP, Cheung MC, Chan WM. Objectivelymeasured neighborhood environments and leisure-time physical activity in Chinese urban elders. Prev Med. 2013;56:86-9.

38. Shores KA, West ST. Rural and urban park visits and park-based physical activity. Prev Med. 2010;50:S13-7.

39. McNaughton SA, Crawford D, Ball K, Salmon J. Understanding determinants of nutrition, physical activity and quality of life among older adults: the Wellbeing, Eating and Exercise for a Long Life (WELL) study. Health Qual Life Out. 2012, 10

40. Craig $C L$, Marshall AL, Sjostrom M, Bauman AE, Booth ML, Ainsworth BE, et al. International physical activity questionnaire: 12-country reliability and validity. Med Sci Sports Exerc. 2003;35:1381-95.

41. Saelens BE, Sallis JF, Black JB, Chen D. Neighborhood-based differences in physical activity: an environment scale evaluation. Am J Public Health. 2003:93:1552-8.

42. Cerin E, Conway TL, Saelens BE, Frank LD, Sallis JF. Cross-validation of the factorial structure of the Neighborhood Environment Walkability Scale (NEWS) and its abbreviated form (NEWS-A). Int J Behav Nutr Phys Act. 2009, 6.

43. Haywood KL, Garratt AM, Fitzpatrick R. Quality of life in older people: a structured review of generic self-assessed health instruments. Qual Life Res. 2005;14:1651-68

44. Ware J, Kosinski M, Keller S. SF-36 Physical and mental health summary scales: a user manual and interpretation guide. Boston: The Health Institute, New England Medical Center; 1994.

45. Cleland V, Sodergren M, Otahal P, Timperio A, Ball K, Crawford D, et al. Associations Between the Perceived Environment and Physical Activity Among Adults Aged 55-65 Years: Does Urban-rural Area of Residence Matter? J Aging Phys Act. 2014, In press.

46. Cheung BY. Zero-inflated models for regression analysis of count data: a study of growth and development. Stat Med. 2002;21:1461-9.

47. Aiken LS, West SG. Multiple regression: testing and interpreting interactions. Newbury Park, CA: Sage; 1991.

48. Evenson K, Wen F, Hillier A, Cohen D. Assessing the contribution of parks to physical activity using global positioning system and accelerometry. Med Sci Sports Exerc. 2013:45:1981-7.

49. Han B, Cohen D, McKenzie TL. Quantifying the contribution of neighborhood parks to physical activity. Prev Med. 2013;57:483-7.

50. Schipperijn J, Bentsen P, Troelsen J, Toftager M, Stigsdotter UK. Associations between physical activity and characteristics of urban green space. Urban For Urban Gree. 2013;12:109-16.

51. Sugiyama T, Francis J, Middleton NJ, Owen N, Giles-Corti B. Associations between recreational walking and attractiveness, size, and proximity of neighborhood open spaces. Am J Public Health. 2010;100:1752-7.

52. Kaczynski AT, Potwarka LR, Smale BJA, Havitz ME. Association of parkland proximity with neighborhood and park-based physical activity: variations by gender and age. Leisure Sci. 2009;31:174-91.

53. Biddle S, Mutrie N. Psychology of physical activity: Determinants, well-being and interventions. 2nd ed. New York: Routledge; 2008.

54. Sugiyama T, Neuhaus M, Cole R, Giles-Corti B, Owen N. Destination and route attributes associated with Adults' walking: a review. Med Sci Sports Exerc. 2012:44:1275-86.

55. Saarloos D, Kim J-E, Timmermans H. The built environment and health introducing individual space-time behavior. Int J Environ Res Publ Health. 2009;6:1724-43.

56. Chen C, Mokhtarian PL. Tradeoffs between time allocations to maintenance activities/travel and discretionary activities/travel. Transport. 2006;33:223-40.

57. Lackey KJ, Kaczynski AT. Correspondence of perceived vs. objective proximity to parks and their relationship to park-based physical activity. Int J Behav Nutr Phys Act. 2009, 6

58. Macintyre S, Macdonald L, Ellaway A. Lack of agreement between measured and self-reported distance from public green parks in Glasgow, Scotland. Int J Behav Nutr Phys Act. 2008, 5.

59. Sallis JF, Owen N. Ecological models of health behavior. In: Glanz K, Rimer BK, Lewis FM, editors. Health Behavior and Health Education: Theory, Research, and Practice. 3rd ed. San Francisco: Jossey-Bass; 2002. p. 462-84.

60. Owen N, Humpel N, Salmon J, Pekka O. Environmental influences on physical activity. In: Oja P, Borms J, editors. Perspectives - the Multidisciplinary Series of Physical Education and Sport Science. Volume 6. Verlag: Meyer \& Meyer; 2004
61. Schipperijn J, Stigsdotter UK, Randrup TB, Troelsen J. Influences on the use of urban green space - A case study in Odense, Denmark. Urban For Urban Gree. 2010;9:25-32.

62. Sallis JF, Saelens BE, Frank LD, Conway TL, Slymen DJ, Cain KL, et al. Neighborhood built environment and income: examining multiple health outcomes. Soc Sci Med. 2009;68:1285-93.

63. Van Dyck D, Cardon G, Deforche B, Sallis JF, Owen N, De Bourdeaudhuij I. Neighborhood SES and walkability are related to physical activity behavior in Belgian adults. Prev Med. 2010;50:574-9.

64. Kaczynski AT, Mowen AJ. Does self-selection influence the relationship between park availability and physical activity? Prev Med. 2011;52:23-5.

\section{Submit your next manuscript to BioMed Central and take full advantage of:}

- Convenient online submission

- Thorough peer review

- No space constraints or color figure charges

- Immediate publication on acceptance

- Inclusion in PubMed, CAS, Scopus and Google Scholar

- Research which is freely available for redistribution 